\title{
The MTHFR C677T Polymorphism and Hyperuricemia Risk: a Meta-analysis of 558 Cases and 912 Controls
}

\section{Rai V*}

Human Molecular Genetics Laboratory, Department of Biotechnology, VBS Purvanchal University, Jaunpur-222001, India

\begin{abstract}
Both genetic and environmental factors play roles in hyperuricemia and susceptibility may be modified by functional polymorphisms in folate metabolic genes, such as methylenetetrahydrofolate reductase (MTHFR). Several case control studies investigated association between C677T polymorphism with hyperuricemia but the sample size was small in these studies and the association power was weak. The aim of the present meta-analysis was to evaluate association between MTHFR C677T polymorphism and hyperuricemia. This meta-analysis recruited 6 published studies which were selected by search of electronic databases up to August 2013, including 558 hyperuricemic cases and 912 healthy controls. Odds ratios (ORs) with $95 \%$ confidence intervals (Cls) were used to assess the association between MTHFR C677T polymorphism and hypeuricemia susceptibility using fixed effect models. Statistically significant relationship was found between C677T polymorphism and hyperuricemia with all genetic models (Additive model T vs. C: OR=1.8401, $95 \% \mathrm{Cl}=1.55-2.18, \mathrm{p}<0.0001$; Homozygote model TT vs. $\mathrm{CC}$ : OR=2.9873, 95\% Cl=2.06-4.33, $\mathrm{p}<0.0001$; Co-dominant CT vs. $C C$ : $O R=2.3785,95 \% \mathrm{Cl}=1.85-3.04, p<0.0001$; Dominant model $\mathrm{TT}+\mathrm{CT}$ vs. $\mathrm{CC}: \mathrm{OR}=2.5233,95 \% \mathrm{Cl}=1.99-3.19$, $p<0.0001$; Recessive model TT vs. $C T+C C$ : OR=2.2628, 95\% Cl=1.61-3.17, $p<0.0001)$. In conclusion, the MTHFR C677T polymorphism was associated with an increased risk of hyperuricemia.
\end{abstract}

Keyword: Hyperuicemia; MTHFR; C677T; Homocysteine; Metaanalysis

\section{Abbreviation: MTHFR: Methylenetetrahydrofolate Reductase \\ Introduction}

Many clinical and epidemiological studies have reported that higher serum uric acid (UA) is related to increased risk of gout, obesity, hypertension hyperlipidemia, renal insufficiency, insulin resistance, cardiovascular and cerebrovascular diseases in general population [1-3]. Elevated serum UA was commonly detected in subjects with abnormal purine metabolism, reflecting overproduction of UA and/or insufficient UA excretion from the kidney. On average, serum UA increases with age $[1,4]$ and is higher in men than in women possibly because of estrogens $[5,6]$ and is considered as a marker of renal dysfunction, as well as a risk factor of renal disease progression.

The uric acid is the end product of purines catabolism and hyperuricemia is the result of imbalance among production (liver) and excretion (renal and fecal) of $70 \%$ and $30 \%$, respectively. In appropriate concentrations, uric acid acts as an antioxidant and in high concentrations (hyperuricemia), acts as pro-oxidant $[7,8]$. Smoking, alcohol intake, purine-rich foods and the renal hypoexcretion resulting from drugs like diuretics are the major causes of hyperuricemia. In addition, several genetic factors have been associated with hyperuricemia. Methylenetetrahydrofolate reductase (MTHFR) gene polymorphism (C677T) is reported as one of these genetic factors in several studied [9-11].

MTHFR is an essential enzyme in metabolizing folate, which catalyzes 5,10-methylenetetrahydrofolate to 5-methyltetrahydrofolate. The product is the dominant form of circulating folate, and provides a methyl group for the remethylation of homocysteine back to methionine. MTHFR gene is composed of twelve exons and is localized on chromosome 1p36.3 [10]. C677T Transition (rs1801133) is a common mutation in the coding region of the MTHFR gene that causes an alanine to valine (Al222Val) substitution [10]. This mutation is associated with reduced MTHFR activity and higher homocysteine levels. Homozygosity for the mutation (TT) predisposes to significantly elevated plasma homocysteine levels [10]. The frequency of the MTHFR 677T allele varies in different ethnic and regional world populations for example, the allele frequency is 0.07 is Sub-Saharan Africans and 0.06 in Canadian Inuit, whereas in Asians the allele frequencies are 0.04-0.54 $(11,23,26)$. Although the mechanism of the relationship between MTHFR polymorphism and serum uric acid is still unknown, some studies have presumed that the MTHFR mutation could affect mechanisms such as the de novo synthesis of purines via 10 -formyl tetrahydrofolate with consequent overproduction of UA by the substrate of the MTHFR reaction.

In present meta-analysis, the estimates of the genetic association of each individual study and a pooled estimate were obtained. In addition, the heterogeneity between studies and the existence of publication bias were investigated.

\section{Methods}

Author assessed the association between the MTHFR C677T polymorphism and hyperuricemia by conducting meta-analysis of all published papers and pooled analysis of individual-level data available.

\section{Search strategy and identification of relevant studies}

Author searched Pubmed, Google Scholar and Springer Link databases online to identify potential relevant epidemiological publications through August 2013 and used the key term

*Corresponding author: Rai V, Human Molecular Genetics Laboratory, Department of Biotechnology, VBS Purvanchal University, Jaunpur-222001, India, Tel: 05452-252344; Fax: 05452-252244; E-mail: raivandana@rediffmail.com

Received January 06, 2016; Accepted January 27, 2016; Published January 29 2016

Citation: Rai V (2016) The MTHFR C677T Polymorphism and Hyperuricemia Risk: a Meta-analysis of 558 Cases and 912 Controls. Metabolomics 6: 166. doi:10.4172/2153-0769.1000166

Copyright: (c) 2016 Rai V. This is an open-access article distributed under the terms of the Creative Commons Attribution License, which permits unrestricted use, distribution, and reproduction in any medium, provided the original author and source are credited. 
Citation: Rai V (2016) The MTHFR C677T Polymorphism and Hyperuricemia Risk: a Meta-analysis of 558 Cases and 912 Controls. Metabolomics 6: 166. doi:10.4172/2153-0769.1000166

Page 2 of 6

"Methylenetetrahydrofolate Reductase", "MTHFR", "C677T” as well as "hyperuricemia" in the search.

Those fulfilling the following criteria were considered eligible for further analysis: 1. Examining the exact topic of concern; 2. Published work with access; 3 . Case-control study providing the individual numbers of all three genotypes of MTHFR (CC, CT and TT) from both case and control groups, or providing gene frequencies and sample sizes, or sufficient data for measuring OR and corresponding 95\%CI.

\section{Data extraction}

Following information were extracted from each study: 1, name of first author; 2, year of publication; 3 , journal name; 4,study design based on the background of control individuals; 5 , country; 6 , total sample size and distribution of each genotype in case and control group respectively.

\section{Statistical analysis}

Crude ORs with 95\% CIs were used to assess the strength of association between the MTHFR C677T polymorphism and hyperuricemia risk. The pooled ORs were performed with additive/ allele contrast model ( $\mathrm{T}$ vs. C), co-dominant model (CT vs. $\mathrm{CC}$ ), homozygote model (TT vs. CC), dominant model (CT+TT vs. CC), and recessive model (TT vs. CC+CT), respectively. Both fixed-effects model [12-14] and random effects [15] model were applied in measurements.

Author also assessed heterogeneity between studies by chi-squarebased Q-test and $\mathrm{I}^{2}$ statistics [16], and a P value less than 0.05 for the Q-test or $\mathrm{I}^{2}$ value greater than $50 \%$ in $\mathrm{I}^{2}$ statistics indicates the existence of heterogeneity between studies, then random-effects model was better for interpretation, otherwise, chose the fixed-effects model results. Additionally, Chi-squared test was used to determine if the observed frequencies of genotypes conformed to Hardy-Weinberg equilibrium expectations.

\section{Publication bias}

Publication bias was investigated with the funnel plot. Funnel plot asymmetry was further assessed by the method of Egger's linear regression test [17]. Analyses were performed using the computer program MIX version 1.7 [ 18]. A p value less than 0.05 was considered statistically significant, and all the p values were two sided.

\section{Results}

\section{Characteristics of included studies}

According to our search strategy and inclusion criteria, five studies with full-text articles were remained the relationship of MTHFR C677T polymorphism with hyperuricemia [19-23]. One author [21] reported male and female samples separately, so author treated them independently. Hence total six studies were found suitable for the inclusion in present meta-analysis. The studies were published between 2000 and 2007. All these five studies were performed in different countries- Korea [20], China [ 22,23] , Iran [21], and Japan [19]. All samples belong to two ethnic populations Caucasian and Asian (Table 1). In all six studies, total cases were 558 with CC (168), CT (299) and TT (91), and controls were 912 with CC (451), CT (371), and TT (90) genotypes. In controls genotypes, percentage of CC, CT and TT were $49.45 \%, 40.68 \%$, and $9.87 \%$ respectively. In total cases, genotype percentage of CC, CT, and TT was $30.11 \%, 53.58 \%$ and $16.31 \%$ respectively. Frequencies of CC and CT genotypes were highest in both cases and controls (Table 2). In cases and controls, the allele $\mathrm{C}$ was the most common. Control samples in all studies were in Hardy Weinberg equilibrium.

\section{Frequency of risk allele in the control population}

To estimate the pooled frequency, author combined case-control studies of MTHFR C677T and extracted data only from the control group. Based on all these samples, the frequency of risk $\mathrm{T}$ allele varied among different ethnicities i e. in Caucasian and Asian: high in Asian healthy populations $35.36 \%$ and low in Caucasian healthy populations $19 \%$.

\section{Meta-analysis using allele frequency}

Mutant $\mathrm{T}$ allele showed significant association with hyperuricemia in both fixed effect $(\mathrm{OR}=1.8401,95 \% \mathrm{CI}=1.55-2.18, \mathrm{p}<0.0001)$ and random effect $(\mathrm{OR}=1.4401,95 \% \mathrm{CI}=1.55-2.18, \mathrm{p}<0.0001)$ models (Table 3 and Figure 1).

\begin{tabular}{|c|c|c|c|c|c|}
\hline Study & Country & Control & Case & Year & Reference \\
\hline Zuo et al. & Japan & 213 & 58 & 2000 & J Hum Genet, 45: 257-262. \\
\hline Hong et al. & Korea & 240 & 87 & 2004 & J Korean Med Sci, 19: 209-213. \\
\hline Gobahar et al (male) & Iran & 153 & 115 & 2006 & Nutr Metab Cardiovasc Dis, 17: 462-467 \\
\hline Golbahar et al.(Female) & Iran & 134 & 116 & 2006 & Nutr Metab Cardiovasc Dis, 17: 462-467 \\
\hline Shi et al. & China & 91 & 90 & 2006 & Chin J Diabetes, 14: 178-181. \\
\hline Yao et al. & China & 81 & 92 & 2007 & Ai Bian Ji Bian Tu Bian, 19: $50-52$. \\
\hline
\end{tabular}

Table 1: Characteristics of six studies included in the present meta-analysis.

\begin{tabular}{|c|c|c|c|c|c|c|c|c|c|c|}
\hline \multirow[t]{3}{*}{ Study ID } & \multicolumn{6}{|c|}{ Genotype } & \multicolumn{4}{|c|}{ Alleles } \\
\hline & \multicolumn{2}{|c|}{ CC } & \multicolumn{2}{|c|}{ CT } & \multicolumn{2}{|c|}{ TT } & \multicolumn{2}{|c|}{ C } & \multicolumn{2}{|c|}{$\mathbf{T}$} \\
\hline & Case & Control & Case & Control & Case & Control & Case & Control & Case & Control \\
\hline Zuo, 2000 & 15 & 96 & 30 & 92 & 13 & 25 & 60 & 284 & 56 & 142 \\
\hline Hong, 2004 & 20 & 97 & 49 & 113 & 18 & 30 & 89 & 307 & 85 & 173 \\
\hline Gobahar, 2006 (male) & 48 & 106 & 57 & 41 & 10 & 6 & 153 & 253 & 77 & 53 \\
\hline Golbahar, 2006 (Female) & 39 & 84 & 68 & 44 & 9 & 6 & 146 & 212 & 86 & 56 \\
\hline Shi, 2006 & 27 & 40 & 42 & 38 & 21 & 13 & 96 & 118 & 84 & 64 \\
\hline Yao, 2007 & 19 & 28 & 53 & 43 & 20 & 10 & 91 & 99 & 93 & 63 \\
\hline
\end{tabular}

Table 2: The distributions of MTHFR C677T genotypes and allele frequencies in hyperuricemic patients and healthy controls. 
Citation: Rai V (2016) The MTHFR C677T Polymorphism and Hyperuricemia Risk: a Meta-analysis of 558 Cases and 912 Controls. Metabolomics 6: 166. doi:10.4172/2153-0769.1000166

Page 3 of 6

\begin{tabular}{|c|c|c|c|c|c|}
\hline Genetic Models & $\begin{array}{l}\text { Fixed effect } \\
\text { OR }(95 \% \mathrm{Cl}), \mathrm{p}\end{array}$ & $\begin{array}{l}\text { Random effect } \\
\text { OR }(95 \% \mathrm{Cl}), p\end{array}$ & $\begin{array}{l}\text { Heterogeneity } p \text {-value } \\
\text { (Q test) }\end{array}$ & $I^{2}(\%)$ & $\begin{array}{l}\text { Publication Bias } \\
\text { ( } p \text { of Egger's test) }\end{array}$ \\
\hline Allele Contrast (T vs C) & $1.84(1.55-2.18),<0.0001$ & $1.44(1.55-2.18),<0.0001$ & 0.734 & $0 \%$ & 0.323 \\
\hline Dominant (TT+CT vs CC) & $2.52(1.99-3.19),<0.0001$ & $2.53(1.99-3.20),<0.0001$ & 0.634 & $0 \%$ & 0.050 \\
\hline Homozygote (TT vs CC) & $2.98(2.06-4.33),<0.0001$ & $3.00(2.06-4.24),<0.001$ & 0.992 & $0 \%$ & 0.283 \\
\hline Co-dominant (CT vs CC) & $2.38(1.85-3.04),<0.0001$ & $2.39(1.86-3.05),<0.0001$ & 0.477 & $0 \%$ & 0.022 \\
\hline Recessive (TT vs CT+CC) & $2.26(1.61-3.17),<0.0001$ & $2.27(1.61-3.17),<0.00001$ & 0.996 & $0 \%$ & 0.886 \\
\hline
\end{tabular}

Table 3: Summary estimates for the odds ratio (OR) of MTHFR C677T in various allele/genotype contrasts, the significance level ( $p$ value) of heterogeneity test ( $Q$ test), $\mathrm{I}^{2}$ metric and publication bias $\mathrm{p}$-value (Egger Test).
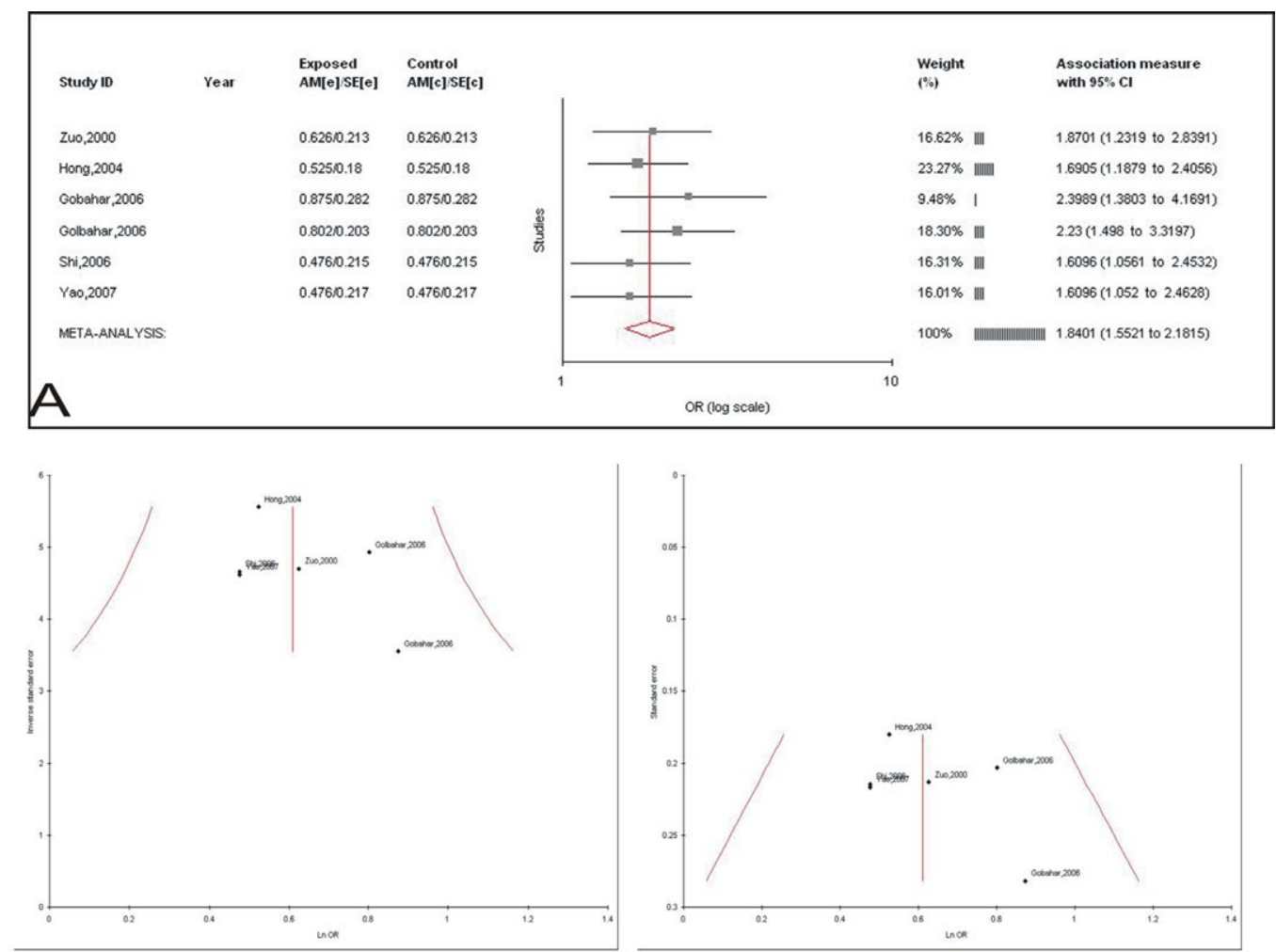

$\mathrm{B}$

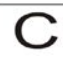

Figure 1A: Forest plots for the association between MTHFR C677T polymorphism and hyperuricemia for additive model (T vs C) with fixed effect model, B. Funnel plot of precision versus OR , C. Funnel plot of standard error versus OR.

\section{Meta-analysis using genotype frequency}

Similar to allele meta-analysis, pooled odds ratio for mutant genotypes $(\mathrm{CT}+\mathrm{TT})$ showed statistically significant association with hyperuricemia adopting both fixed $(\mathrm{OR}=2.5233,95 \% \mathrm{CI}=1.99-3.19$, $\mathrm{p}<0.0001)$ and random $(\mathrm{OR}=2.5303,95 \% \mathrm{CI}=1.99-3.20, \mathrm{p}<0.0001)$ effect models (Figure 2). Association was also detected between the C677T polymorphism and the susceptibility to hyperuricemia in all other three genetic models (for TT vs. CC (homozygote model): $\mathrm{OR}=2.9873,95 \% \mathrm{CI}=2.06-4.33, \mathrm{p}<0.0001$; for $\mathrm{TT}$ vs. CT + CC (recessive model): $\mathrm{OR}=2.2628,95 \% \mathrm{CI}=1.61-3.17, \mathrm{p}<0.0001$; for $\mathrm{CT}$ vs. CC (codominant model): OR=2.3785, 95\% CI=1.85-3.04, $\mathrm{p}<0.0001$ ) (Table 3 and Figure 3).

\section{Sensitivity analysis}

In the sensitivity analysis, the influence of each study on the pooled OR was examined by repeating the meta-analysis while omitting each study, one at a time. This procedure confirmed the stability of present meta-analysis result (data not shown).

\section{Publication bias}

Funnel plots were generated using standard error and precision values and $\log$ OR using fixed effect models (Figures 1-3). Symmetrical distribution of studies in the funnel plots suggests absence of publication bias. This is also supported by other tests. Begg's funnel plot and the Egger's test were conducted to estimate the publication bias of articles. Both the results of Begg's and Egger's test did not show any evidence of publication bias except co-dominant model (T vs $C$ Begg's test, $P=1.000$, Egger's test, $P=0.323$; CT vs. CC Begg's test, $P=0.259$, Egger's test, $P=0.022$; TT vs CC Begg's test, $P=0.259$, Egger's test, $P=0.283$; Dominant model, Begg's test, $P=0.259$, Egger's test, $P=0.05$; Recessive model, Begg's test, $P=1.000$, Egger 's test, $P=0.886$ ) (Table 3 and Figure 3). 
Citation: Rai V (2016) The MTHFR C677T Polymorphism and Hyperuricemia Risk: a Meta-analysis of 558 Cases and 912 Controls. Metabolomics 6: 166. doi:10.4172/2153-0769.1000166

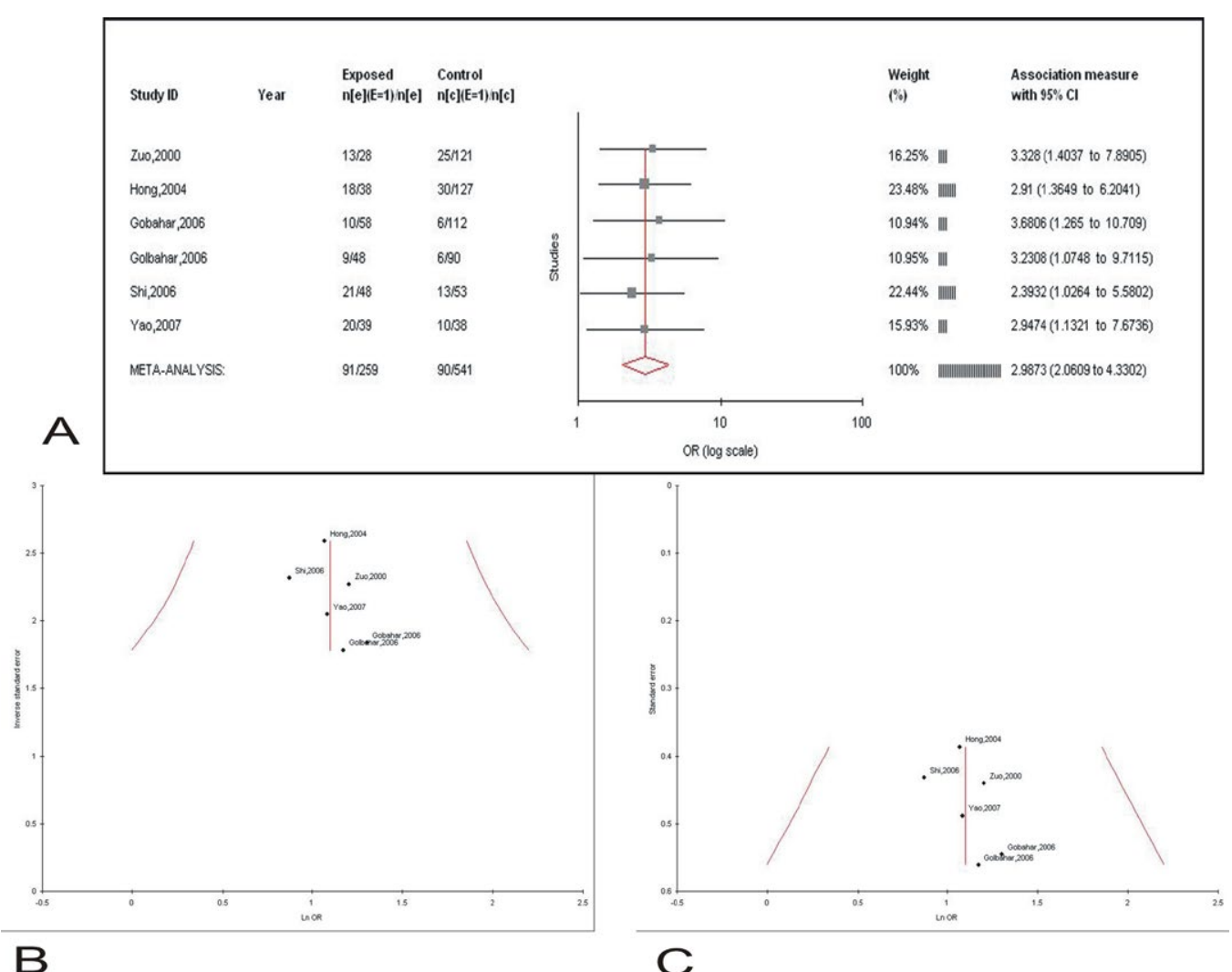

Figure 2 A: Forest plots for the association between MTHFR C677T polymorphism and hyperuricemia for homozygote model (TT vs CC) with fixed effect model, B. Funnel plot of precision versus OR , C. Funnel plot of standard error versus OR.

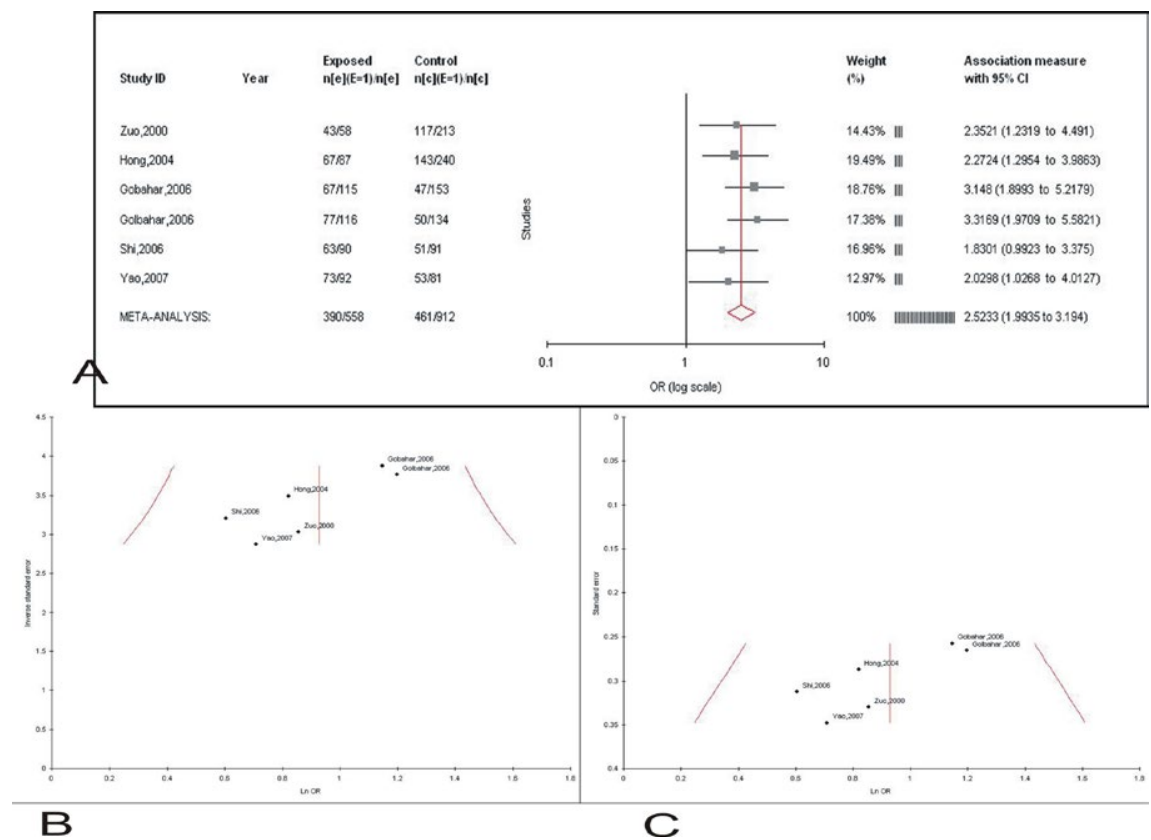

Figure 3 A: Forest plots for the association between MTHFR C677T polymorphism and hyperuricemia for dominant model (TT+CT vs CC) with fixed effect model, B. Funnel plot of precision versus OR , C. Funnel plot of standard error versus OR. 
Citation: Rai V (2016) The MTHFR C677T Polymorphism and Hyperuricemia Risk: a Meta-analysis of 558 Cases and 912 Controls. Metabolomics 6: 166. doi:10.4172/2153-0769.1000166

Page 5 of 6

\section{Discussion}

Meta-analysis is a powerful tool for analyzing cumulative data of studies where the individual sample sizes are small and the statistical power low and during past decade several meta-analyses were published assessing MTHFR as risk factor to various diseases/disorders like Cardiovascular disease [24], diabetes [25], Cancer [11] and psychiatric disorder [26-28] etc. The present meta-analysis examining MTHFR C677T in 558 patient and 912 control subjects indicated that carriers of the $\mathrm{T}$ allele and TT genotype are at a statistically significant increased risk of hyperuricemia.

Motti and coworkers reported significant association between MTHFR C677T polymorphism and serum UA in Italian population [29]. Their study showed that in TT individuals there was a positive correlation between homocysteine and serum uric acid concentrations. In 2000, Zuo et al. reported C677T polymorphism as risk factor for hyperuricemia in older Japanese subjects. Similar results were observed by Hong et al. in Korean population. Golbahar et al. carried out this analysis in male and female samples separately and found significant association between UA and MTHF C677T polymorphism in both groups. On the other hand, there were 2 studies [22,23] reporting association between the MTHFR 677TT genotype and SUA mean in Chinese.

MTHFR 677T allele is associated with higher homocysteine concentration [30-36]. Dysfunction of homocysteine metabolism has been linked to several disorders, including neural tube defects (NTDs) [37], stroke [38] and syndromes [39]. Significant association between hyperhomocysteinemia and serum uric acid was reported in atherosclerotic patients in several studies [38].

Higher concentration of homocysteine was risk factor for vascular diseases/atherosclerosis, and in TT subjects due to higher homocysteine concentration, vascular disease or renovascular atherosclerosis occurs and clearance of uric acid may reduce resulting in elevation of serum uric acid [39]. In addition adenosine originating from S-adenosylhomocysteine, and preferentially incorporated into a precursor pool for uric acid, and would link the syntheses of homocysteine and uric acid $[12,29]$

The limitations of the present meta-analysis are (i) small number of studies (only six studies), (ii) small sample size (1470 samples), (iii) different ethnic backgrounds of the individuals included in the study, (iv) widely spread exclusion and inclusion criteria which might complicate the comparison between the studies. Undoubtedly, all the limitations will inevitably affect the summary results, but the strength of present meta-analysis is based on the accumulating studies, and thus has much better power to reach a more precise estimation.

In conclusion, results of present meta-analysis suggest that the MTHFR C677T allele is significant risk of hyperuricemia. Future large-scale, population-based association studies are now required to investigate potential gene-gene and gene-environment interactions involving the MTHFR C677T polymorphism in determining hyperuricemia risk. The sample size was rather small and further studies with large number of subjects are necessary for confirming the result of this meta-analysis.

\section{Acknowledgement}

The author is highly grateful to Leon Bax (Chief Scientific Officer at BiostatXL, UMC Utrecht) for his valuable suggestions, which help us in statistical analysis.

\section{References}

1. Culleton BF, Larson MG, Kannel WB, Levy D (1999) Serum uric acid and risk for cardiovascular disease and death: The Framingham Heart Study. Ann Inter Med 131: 7-13

2. Wheeler JG, Juzwishin KD, Eiriksdotti, G, Gudnason V, Danesh J (2005) Serum uric acid and coronary heart disease in 9,458 incident cases and 155,084 controls: prospective study and meta-analysis. PLoS Med 2: e76.

3. Perlstein TS, Gumieniak O, Williams GH, Sparrow D, Vokonas PS, et al. (2006) Uric acid and the development of hypertension: the normative aging study. Hypertension 48: 1031-1036.

4. Kuzuya M, Ando F, Iguchi A, Shimokata H (2002) Effect of aging on serum uric acid levels: longitudinal changes in a large Japanese population group. J Gerontol 57: 660-664.

5. Sumino H, Ichikawa S, Kanda T, Nakamura T, Sakamaki T (1999) Reduction of serum uric acid by hormone replacement therapy in postmenopausal women with hyperuricaemia. Lancet 354: 650 .

6. Simon JA, Lin F, Vittinghoff E, Bittner V (2006) The relation of postmenopausal hormone therapy to serum uric acid and the risk of coronary heart disease events: the Heart and Estrogen-Progestin Replacement Study (HERS). Ann Epidemiol 16: 138-145.

7. Hayden MR, Tyagi S (2004) Uric acid: a new look at an old risk marker for cardiovascular disease, metabolic syndrome, and type 2 diabetes mellitus: the urate redox shuttle. Nutr Metab 1: 1-10.

8. Hegele RA, Tully C, Young TK, Connelly PW (1997) V677 mutation of methylenetetrahydrofolate reductases and cardiovascular disease in Canadian Inuit. Lancet 349: 1221-1222.

9. Hong YS, Lee MJ, Kim KH, Lee SH, Lee YH, et al. (2004) The C677 mutation in methylene tetrahydrofolate reductase gene: correlation with uric acid and cardiovascular risk factors in elderly Korean men. J Korean Med Sci 19 209-213.

10. Goyette P, Pai A, Milos R, Frosst P, Tran P, et al. (1998) Gene structure of human and mouse methylenetetrahydrofolate reductase (MTHFR). Mamm Genome 9: 652-656.

11. Liang H, Yan Y, Li T, Li R, Li M, et al. (2013) Methylenetetrahydrofolate reductase polymorphisms and breast cancer risk in Chinese population: a meta-analysis of 22 case-control studies.Tumor Bio 35: 1695-701.

12. Malinow MR, Levenson J, Giral P, Nieto FJ, Razavian M, et al. (1995) Role of blood pressure, uric acid, and hemorheological parameters on plasma homocyst(e)ine concentration. Atherosclerosis 114: 175-183.

13. Mantel N, Haenszel W (1959) Statistical aspects of the analysis of data from retrospective studies of disease. J Natl Cancer Inst 22: 719-748.

14. Pepe G, Venegas OC, Giusti B, Brunelli T, Marucci R, et al. (1998) Heterogeneity in world distribution of thermolabile C677T mutation in 5,10-methylenetetrahydrofolate reductase. Am J Hum Genet 63: 917-920.

15. DerSimonian R, Laird N (1986) Meta-analysis in clinical trials. Control Clin Trials 7: 177-188.

16. Higgins JP, Thompson SG (2002) Quantifying heterogeneity in a meta-analysis Stat Med 21: 1539-1558.

17. Egger M, Smith DJ, Schneider M, Minder C (1997) Bias in meta-analysis detected by a simple, graphical test. BMJ 315: 629-634.

18. Bax L, Yu LM, Ikeda N, Tsuruta H, Moons KG (2006) Development and validation of MIX: comprehensive free software for meta-analysis of causal research data. BMC Med Res Methodol 6: 50.

19. Zuo M, Nishio H, Lee MJ, Maejima K, Mimura S, et al. (2000) The C677T mutation in the methylene tetrahydrofolate reductase gene increases serum uric acid in elderly men. J Hum Genet 45: 257-262.

20. Golbahar J, Aminzadeh MA, Al-Shboul QM, Kassab S, Rezaian GR (2006) Association of methylenetetrahydrofolate reductase (C677T) polymorphism with hyperuricemia. Nutr Metab Cardiovasc Dis 17: 462-467.

21. Shi HY, Dong YH, Nan HT, Qian WW, Qian RL (2006) The association of methylenetetrahydrofolate reductase (MTHFR) gene C677T mutation with hyperuricemia. Chin J Diabetes 14: 178-181. 
Citation: Rai V (2016) The MTHFR C677T Polymorphism and Hyperuricemia Risk: a Meta-analysis of 558 Cases and 912 Controls. Metabolomics 6: 166. doi:10.4172/2153-0769.1000166

22. Yao $H$, Ding LL, Wang XM Xu FL (2007) Polymorphisms of methylenetetrahydrofolate reductase $\mathrm{C} 677 \mathrm{~T}$ and hyperuricemia in males. A Bian Ji Bian Tu Bian 19: 50-52.

23. Xuan C, Bai XY, Gao G, Yang Q, He GW (2011) Association between polymorphism of methylenetetrahydrofolate reductase (MTHFR) C677T and risk of myocardial infarction: A meta-analysis for 8,140 cases and 10,522 controls. Arch Med Res 42: 677-685.

24. Yang S, Zhang J, Feng C, Huang G (2013) MTHFR 677 T variant contributes to diabetic nephropathy risk in Caucasian individuals with type 2 diabetes: $A$ meta-analysis. Metabolism 62: 586-594.

25. Rai $V$ (2011) Evaluation of methylenetetrahydrofolate reductase gene varian (C677T) as risk factor for bipolar disorder. Cell Mol Biol 57: OL1558-OL1566.

26. Rai V, Yadav U, Kumar P (2012) Genotype prevalence and allele frequencies of 5,10-methylenetetrahydrofolate reductase (MTHFR) C677T mutation in two caste groups of India. Cell Mol Biol 58: OL1695-OL1701.

27. Wu YL, Ding XX, Sun YH, Yang HY, Chen J, Zhao X, et al. (2013) Association between MTHFR C677T polymorphism and depression: An updated metaanalysis of 26 studies. Prog Neuropsychopharmacol Biol Psychiatry 46: 78-85.

28. Motti C, Gnasso A, Bernardini S, Massoud R, Pastore A, et al. (1998) Common mutation in methylenetetrahydrofolatereductase. Correlation with homocysteine and other risk factors for vascular disease. Atherosclerosis 139: 377-383.

29. Frosst $P$, Blom HJ, Milos R, Goyette P, Sheppard CA, et al. (1995) A candidate genetic risk factor for vascular disease: a common mutation in methylenetetrahydrofolate reductase. Nat Genet 10: 111-113.

30. Jacques PF, Bostom AG, Williams RR, Ellison RC, Eckfeldt JH, et al. (1996) Relation between folate status, a common mutation in methylenetetrahydrofolate reductase, and plasma homocysteine concentrations. Circulation 93: 7-9.
31. Christensen B, Frosst P, Lussier-Cacan S, Selhub J, Goyette P, et al. (1997) Correlation of a common mutation in the methylenetetrahydrofolate reductase gene with plasma homocysteine in patients with premature coronary artery disease. Arterioscler Thromb Vasc Biol 17: 569-573.

32. Rozen R (1997) Genetic predisposition to hyperhomocysteinemia: deficiency of methelenetetrahydrofolate reductase (MTHFR). Thromb Haemost 78: 523-526.

33. van der Put, NM, Steegers-Theunissen RP, Frosst P, Trijbels FJ, Eskes TK et al. (1995) Mutated methylenetetrahydrofolate reductase as a risk factor for spina bifida. Lancet 346: 1070-1071.

34. van der Put NM, Gabreëls F, Stevens EM et al. (1998) A second common mutation in the methylenetetrahydrofolate reductase gene: an additional risk factor for neural-tube defects? Am J Hum Genet 62: 1044-1051.

35. Kluijtmans LA, Young IS, Boreham CA, Murray L, McMaster D, et al.(2003) Genetic and nutritional factors contributing to hyperhomocysteinemia in young adults. Blood 101: 2483-2488.

36. van der Put NM, van den Heuvel LP, Steegers-Theunissen RP, Trijbels FJ, Eskes TK, et al. (1996) Decreased methylene tetrahydrofolate reductase activity due to the $677 \mathrm{C}-->$ T mutation in families with spina bifida offspring. $J$ Mol Med 74: 691-694.

37. Coull BM, Malinow MR, Beamer N, Sexton G, Nordt F, et al. (1990) Elevated plasma homocysteine concentration as a possible independent risk factor for stroke. Stroke 21: 572-576.

38. Hobbs CA, Sherman SL, Yi P, Hopkins SE, Torfs CP, et al. (2000) Polymorphisms in genes involved in folate metabolism as maternal risk factors for Down Syndrome. Am J Hum Genet 623: 630.

39. Itoua S, Gotob Y, Suzukic K, Kawaib S, Naitob M, et al. (2009) Significant association between methylenetetrahydrofolate reductase $677 \mathrm{~T}$ allele and hyperuricemia among adult Japanese subjects. Nutr Res 29: 710-715. 